\title{
BMJ Global Health Forty-two years of responding to Ebola virus outbreaks in Sub-Saharan Africa: a review
}

\author{
Sima Rugarabamu, ${ }^{1,2}$ Leonard Mboera, ${ }^{1}$ Mark Rweyemamu, ${ }^{1}$ \\ Gaspary Mwanyika, ${ }^{1,3}$ Julius Lutwama, ${ }^{4}$ Janusz Paweska, ${ }^{5}$ Gerald Misinzo ${ }^{1}$
}

To cite: Rugarabamu S, Mboera L, Rweyemamu M, et al. Forty-two years of responding to Ebola virus outbreaks in Sub-Saharan Africa: a review. BMJ Global Health 2020;5:e001955. doi:10.1136/ bmjgh-2019-001955

Handling editor Alberto L Garcia-Basteiro

Received 3 September 2019 Revised 16 January 2020 Accepted 27 January 2020
Check for updates

\section{Author(s) (or their} employer(s)) 2020. Re-use permitted under CC BY-NC. No commercial re-use. See rights and permissions. Published by BMJ.

For numbered affiliations see end of article.

Correspondence to Dr Sima Rugarabamu; sima.rugarabamu@sacids.org

\section{ABSTRACT}

Introduction Ebola virus disease (EVD) is one of the deadliest haemorrhagic fevers affecting humans and nonhuman primates. Thirty-four outbreaks have been reported in Africa since it was first recognised in 1976. This review analysed 42 years of EVD outbreaks and identified various challenges and opportunities for its control and prevention in Sub-Saharan Africa.

Methods A literature search of relevant articles on EVD was done in PubMed, Web of Science and Google Scholar electronic databases. Articles published from 1976 to 2019 were reviewed to document reports of EVD outbreaks in Sub-Saharan Africa. Data extraction focused on the year of outbreak, geographical spread, virus strain involved, number of cases and deaths, case fatality, and outbreak management. Analyses of trends in case fatality were performed by calculating ORs between times.

Results In the past four decades, a total of 34 EVD outbreaks affecting 34356 cases and causing 14823 deaths were reported in 11 countries in Sub-Saharan Africa. The overall case fatality rate $(95 \% \mathrm{Cl})$ was $66 \%$ (62 to 71) and did not change substantially over time (0R in 2019 vs $1976=1.6$ ( $95 \% \mathrm{Cl} 1.5$ to 1.8$), p<0.001)$. The results of this review indicate that challenges to control EVD outbreaks are related to epidemiological, sociocultural and health system factors.

Conclusions Sub-Saharan Africa continues to face considerable challenges in EVD control, whereby there are no significant changes in case fatality rates observed during the past four decades. Socioeconomic and cultural processes need to be critically considered to shape the community behaviours that lead to exposure to EVD outbreaks. Areas that need to be addressed to prevent future EVD outbreaks include a broad-based, one-health approach, effective communication, social mobilisation, and strengthening of the health systems.

\section{INTRODUCTION}

Ebola virus disease (EVD) is a severe, often fatal, illness in humans and non-human primates caused by a highly virulent RNA virus. It is transmitted mainly through contact with blood or body fluids of a person/animal that has contracted or died from the disease. Transmission through contaminated objects

\section{Key questions}

What is already known?

- The unprecedented scale of recent Ebola virus disease (EVD) epidemics is attributed to a combination of factors, including large urban population, minimal public health infrastructure, political instability, extensive connectivity of the population and livelihood practices.

- Rapid case identification and response are key to ending EVD outbreaks through efficient surveillance, laboratory diagnosis, effective coordination and a strong workforce.

What are the new findings?

- A total of 34 EVD outbreaks affecting 34356 cases and causing 14823 deaths have been reported since 1976.

- No significant changes in EVD case fatality rates were observed during the past four decades.

- EVD outbreaks are influenced by changes in contextual conditions, whereby socioeconomic and cultura processes shape behaviours leading to exposure and disease outbreak.

\section{What do the new findings imply?}

- Socioeconomic and cultural factors need to be critically considered to shape the community behaviours that lead to exposure to EVD outbreaks.

- Broad-based, one-health approach, effective communication, social mobilisation, and strengthening of the health systems need to be addressed to prevent future outbreaks.

such as needles and with infected animals or bushmeat has been reported. ${ }^{1}$ EVD was first recognised when two large outbreaks occurred in South Sudan and the Democratic Republic of Congo (DRC) in $1976 .{ }^{23}$ Thereafter, EVD outbreaks have been reported in 1994 and 1995 in Uganda and the DRC, respectively. ${ }^{4}$ Frequent large outbreaks have since been reported from Gabon, DRC, Uganda, Guinea, Liberia, Sierra Leone and Nigeria. ${ }^{1}{ }^{5-7}$ Isolated EVD outbreaks have been reported in South Africa, USA, UK and 
Italy. ${ }^{8}$ There has been an increase in EVD outbreaks in Africa, probably because of increased contact of humans with wildlife due to extensive deforestation, hunting and mining, ${ }^{19}$ as well as improved communications. ${ }^{1011}$

EVD is caused by an RNA Ebolavirus of the family Filoviridae. So far, five species of the genus Ebolavirus have been identified. They include Zaire ebolavirus (ZEBOV), Bundibugyo ebolavirus (BEBOV), Sudan ebolavirus (SEBOV), Reston ebolavirus and Côte d'Ivoire ebolavirus. Most of the outbreaks in Africa were associated with ZEBOV, SEBOV and BEBOV. ${ }^{12}$ Ebolaviruses are found in central and western African rainforests, approximately within $10^{\circ}$ north and south of the equator. ${ }^{9}$ African tropical rainforests, for example, the Western Congo swamp forests and the Minkebé forest in Gabon, have been reported to constitute a common ecosystem for the emergence of Ebolavirus, providing rich animal biodiversity. ${ }^{10} \mathrm{EVD}$ outbreaks are seasonal, occurring mainly during wet seasons, marked by fruit abundance. ${ }^{89}$

Before 2013, EVD outbreaks consisted of relatively small numbers of cases, mostly in rural areas, and were effectively contained by basic public health, quarantine and containment measures. However, the most recent epidemics have changed fundamentally the perception and understanding of the epidemiology of EVD, affecting larger populations and extending to urban areas. The unprecedented scale of these recent epidemics has been attributed to a combination of factors, including large urban population, minimal public health infrastructure, political instability and extensive connectivity of the populations. ${ }^{1011}$

With the number of countries affected by EVD increasing, there is an urgent need for effective vaccines, antiviral drugs and monoclonal antibodies to be authorised and made available for its prevention or treatment. ${ }^{911}$ Sub-Saharan countries need to strengthen their health systems and address the gaps in the management and control of the EVD epidemics. This review aimed to analyse 42 years of Ebola virus outbreak reports, identify challenges and opportunities in its detection and response in Sub-Saharan Africa, and propose the way forward.

\section{METHODS}

\section{Literature search and selection of articles}

An internet search of articles on EVD in Africa that were published from July 1976 to July 2019 was carried out. The main electronic databases involved were PubMed, Web of Science and Google Scholar. Additional information and relevant grey literature were identified and retrieved from various sources including WHO, Global Health (Ovid), Embase, Medline (Ovid), POPline and reports from some of the affected countries. The keywords used were Ebola, Ebola haemorrhagic fever, EVD, outbreaks, epidemics, challenges, diagnosis, case management, control and Africa. The inclusion criteria were all articles published in English, scholarly written articles, articles with abstract, full articles and related articles on EVD in Sub-Saharan Africa published during the period under review. The selection process of all articles included is summarised in figure 1 .

\section{Patient and public involvement}

Patients and/or the public were not involved in the design, conduct, reporting or dissemination plans of this research.

\section{Data extraction and analysis}

Data extraction focused on the year of the outbreak, the geographical spread (estimated area covered, country and region), the strain of the virus involved, the number of cases and deaths, case fatality rate, the challenges, and management used to control the situation. ORs were calculated as described previously. ${ }^{13}$ Additional analyses of trends in case fatality rates were performed by calculating ORs between periods using MedCalc statistical software (https://www.medcalc.org/calc/odds_ratio.php). Critical appraisal was undertaken, and the findings of the relevant studies were analysed and summarised using thematic analysis.

\section{RESULTS}

The internet search retrieved a total of 2539 articles. After screening of titles and abstracts, 125 full-text articles were selected and read in full, and 100 studies were included in the final review (figure 1).

\section{Trends in Ebola outbreaks}

Since 1976, when EVD was first detected in DRC, 34 outbreaks with 1-10000 cases per outbreak have been reported in 11 countries in Africa. The affected countries include the DRC, South Sudan, Uganda, Mali, Nigeria, Sierra Leone, Guinea, Liberia, South Africa, Gabon and Côte d'Ivoire (figure 2).

Ebola is endemic in East-Central and West Africa and is usually dormant in still unknown reservoirs. However, it periodically infects local human populations, causing extensive mortalities, followed by fading out before widespread (table 1). ${ }^{14-16}$ The prevalence and diversity of ZEBOV are high compared with SEBOV, Taï Forest ebolavirus and BEBOV. ${ }^{17-19}$ Previous outbreaks occurred in a geographically isolated community in Africa or from the laboratory accident elsewhere, and have remained small. ${ }^{20}$ The largest and widespread EVD outbreak was observed in West Africa (Guinea, Sierra Leone and Liberia) and DRC. ${ }^{142021}$

\section{Context of EVD}

Different underlying drivers including natural susceptibility of hosts, human economically driven environmental changes and the efficiency of healthcare systems have been described as factors that resulted in EVD outbreaks. ${ }^{22}$ Local and international movement of people has been an important component in the dissemination of virus, causing global threat. ${ }^{23}$ Although there 


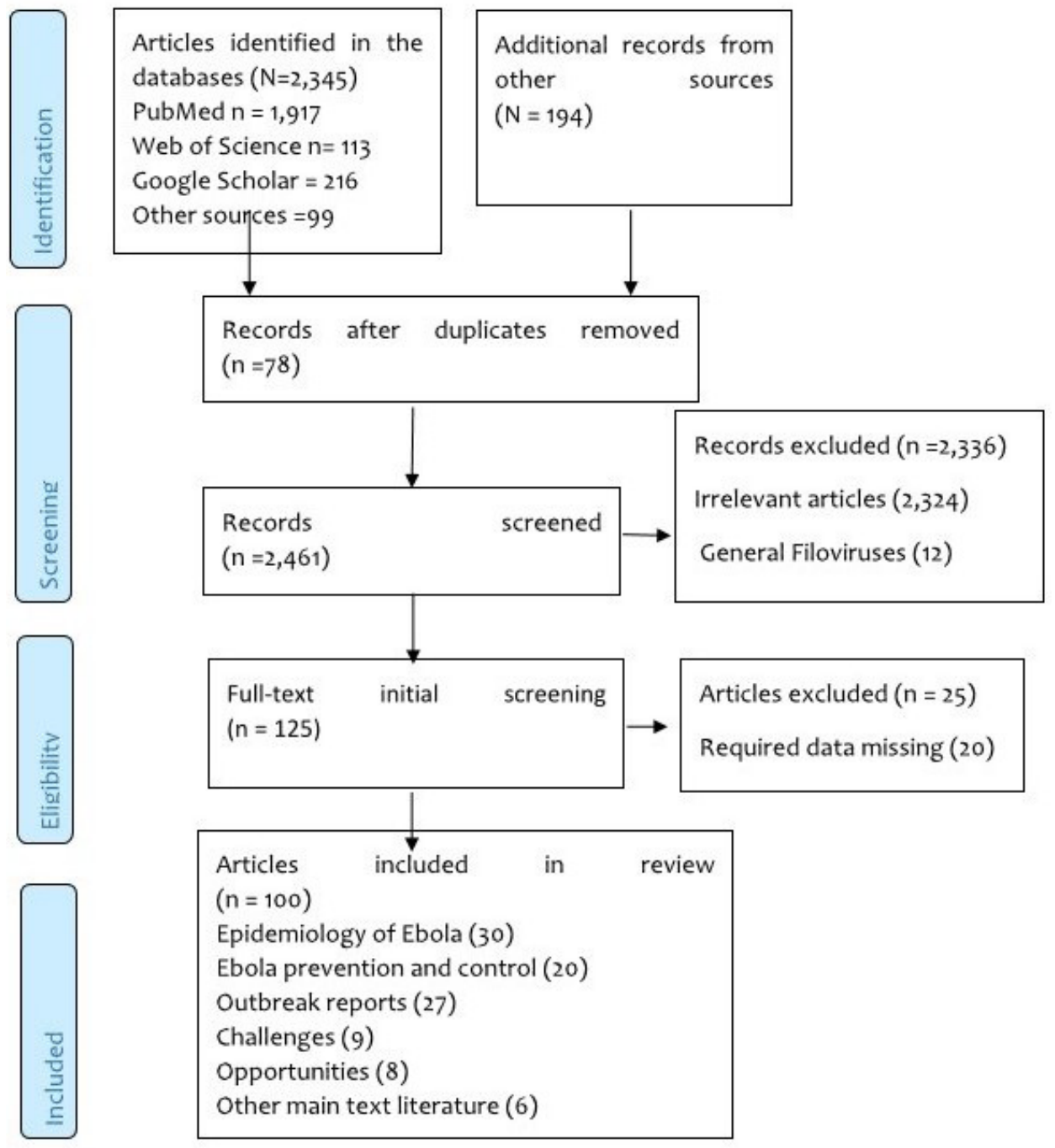

Figure 1 PRISMA flow diagram showing the selection process of articles included in the review. PRISMA, Preferred Reporting Items for Systematic Reviews and Meta-Analyses.

is no evidence related to biological differences in female or male sex that increase EVD transmission and vulnerability, differences in the level of exposure between men and women have been described.

For instance, in the recent EVD outbreak in DRC, women were reported to be most affected due to their occupational and domestic caregiving role. ${ }^{24}$ In most Ebola outbreaks, the transmission rate has been higher in the household than in hospital settings. ${ }^{25}$ Due to the easy human-to-human transmission of the virus through close contact with infected patients, possibly through droplets from sneezes and coughs, medical workers are also considered a high-risk population. Little information is available as regards to the different susceptibility to the genetics of the affected individuals. ${ }^{24-26}$

Currently, aggressive supportive care and management by experimental drugs and vaccines as well as fluid intake are used to improve patient survival. Rapid diagnostic tests that detect viral protein and those based on PCR that identify virus's genomic material are available to support clinical care. To fast-track countries' access to reliable testing options, the WHO approved an in vitro reverse transcription (RT)-PCR diagnostic product, RealStar Filovirus Screen RT-PCR Kit 1.0, which was assessed under an emergency quality assessment mechanism. ${ }^{9} 27$ Early case diagnosis and isolation of patients with EVD during outbreaks remain an important component in disease prevention. ${ }^{27} \mathrm{~A}$ surveillance system is essential in the control measures required to reduce morbidity and mortality caused by EVD. Control strategies during an Ebola outbreak include proactive case detection, contact tracing and management, safe and dignified burials, and prevention of new infections. ${ }^{27} 28$

During the past four decades, approximately 14853 people have died from EVD outbreaks. Most (70\%) of the cases were individuals aged $15-60$ years old (table 2). All the sources of known index cases of Ebola have been traced to the hunting of bushmeat or exposure to dead animals in the rainforest. ${ }^{1}$ Every case except that of the index patient could be traced to a human source of infection. ${ }^{2629}$ 


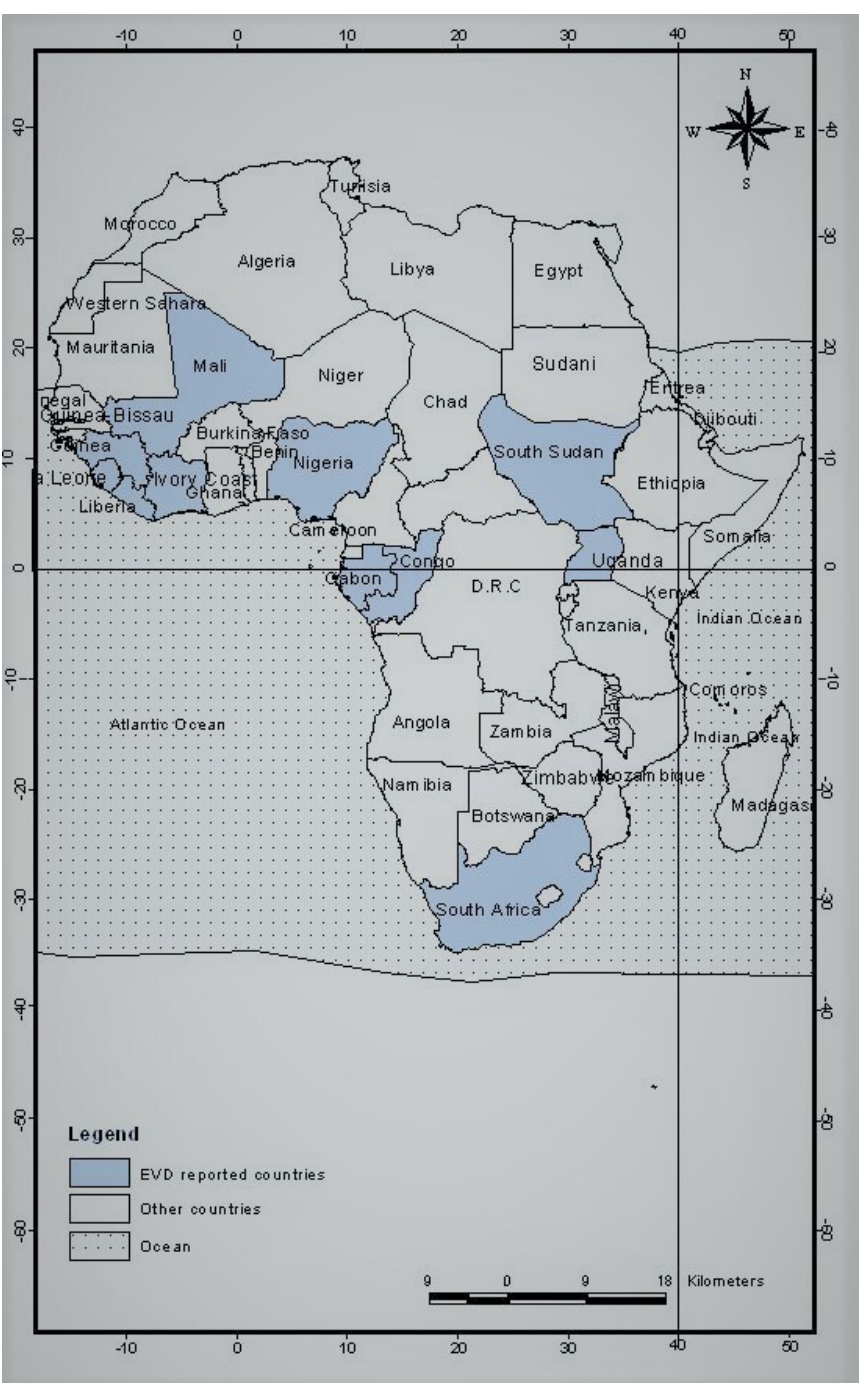

Figure 2 Map showing the 11 African countries affected by Ebola virus disease since 1976.

Case fatality rates varied from $71 \%$ during outbreaks in $1976-1986$ to $62 \%$ during the later years. However, there was no statistically significant change over time (OR in 2019 vs 1976: 1.6 (95\% CI 1.5 to 1.6$)$ ). The overall trend from 1976 to 2019 outbreaks shows a linear rate of change over time (table 3 , figure 3 ).

\section{Challenges and opportunities in EVD control}

Challenges in the detection and containment of EVD outbreaks include epidemiological and ecological, health system, and sociocultural factors (table 4).

\section{Epidemiological and ecological factors}

While the specific source of EVD in most outbreaks is not known, the pathogen is thought to be harboured in some species of bats, with initial transmission to humans via butchering or consumption of bats or other infected animal species, and then spread through human-tohuman transmission. ${ }^{30}$ Ebola viruses are endemic in central and western African rainforests, approximately within $10^{\circ}$ north and south of the equator. ${ }^{30}$ Consequently, the sporadic emergency and spillover of the
Ebola virus are supported by and likely to be associated with some intrinsic factors related to these forest systems. $^{28}$ Outbreaks of Ebola virus since 1976 have been occurring in what is described as the 'Ebola Forest Belt'. The forest ecotypes provide habitats for diverse fauna. ${ }^{30}$ Alterations of the natural ecosystem as a result of human influences and natural ecological processes, such as land use for agricultural intensification and livestock grazing purposes or rural urbanisation, have increased proximity between human population and wildlife, leading to enhanced contacts with Ebola virus-carrying natural hosts.

Humans continuously interact with the biotic and abiotic components of the forest ecotype in complex ways which drive and facilitate spillover events. For instance, the first EVD case in DRC in 1976 was a male teacher who reported having purchased fresh and smoked antelope and monkey meat. ${ }^{2}$ Activities such as hunting are performed by men compared with women within the African context. ${ }^{26}$ The increase in Ebola outbreaks in DRC since 1994 has been associated with changes in forest ecosystems due to deforestation, which displaces bats. The part of Guinea where the West African EVD outbreak of 2014-2016 started has been largely deforested. Moreover, wars in Liberia and Sierra Leone and corruption in Guinea caused poverty, leading people to migrate for work and spreading the virus further. ${ }^{26} 3233$

Growth of cities and rural urbanisation as a result of an increase in population density are among the factors associated with EVD outbreaks in Sub-Saharan Africa. ${ }^{34}$ EVD transmission is ecologically linked more to rural settings, where extreme poverty exists and health systems are relatively weak. ${ }^{3536}$ Effective isolation and control of EVD-infected patients in such contexts are difficult. ${ }^{31} 3536$

\section{Therapeutics and vaccines}

Past EVD outbreaks were small, confined to one community, and were contained within relatively short periods of time by detecting and isolating cases. ${ }^{37-39}$ In such outbreaks, case management processes included replacement of fluids and electrolytes and control of symptoms. The increased frequency of outbreaks urged the need for additional therapies and vaccines to manage the disease. Appropriate case management may potentially improve recovery and survival. ${ }^{39-42}$ Clinical trials of potential therapy and vaccines to determine safety and efficacy can only be conducted during an outbreak, which most often is faced with enormous challenges. In 2013, three therapeutic products (ZMapp, small inhibitory RNA and antisense phosphorodiamidate morpholino oligomers) which were reported to provide $100 \%$ protection in infected monkeys were submitted to WHO to be used during the West African epidemic. Their safety to patients remains unknown because the supplies were limited and/ or not enough to conduct trials. ${ }^{6}$ Testing these drugs in animals infected with Ebola is hampered by the fact that they must be done in participating biosafety level 4 laboratories, which are limited in Africa. A major issue 
Table 1 EVD outbreaks, virus type, morbidity, mortality and case fatality rate in affected countries

\begin{tabular}{|c|c|c|c|c|c|}
\hline Year & Country & Virus & Cases & Deaths & CFR $(\%)^{*}$ \\
\hline 1976 & Democratic Republic of Congo & EBOV & 318 & 280 & 88 \\
\hline 1976 & South Sudan & SUDV & 284 & 151 & 53 \\
\hline 1977 & Democratic Republic of Congo & EBOV & 1 & 1 & 100 \\
\hline 1979 & South Sudan & SUDV & 34 & 22 & 65 \\
\hline 1994 & Gabon & EBOV & 52 & 31 & 60 \\
\hline 1994 & Côte d'Ivoire & TAFV & 1 & 0 & 0 \\
\hline 1995 & Democratic Republic of Congo & EBOV & 315 & 250 & 79 \\
\hline 1996 & Gabon & EBOV & 37 & 21 & 57 \\
\hline 1996-1997 & Gabon & EBOV & 60 & 45 & 75 \\
\hline 1996 & South Africa & EBOV & 2 & 1 & 50 \\
\hline 2000-2001 & Uganda & SUDV & 425 & 224 & 53 \\
\hline 2001-2002 & Gabon & EBOV & 65 & 53 & 82 \\
\hline 2001-2002 & Republic of Congo & EBOV & 57 & 43 & 75 \\
\hline 2002-2003 & Republic of Congo & EBOV & 143 & 128 & 89 \\
\hline 2003 & Republic of Congo & EBOV & 35 & 29 & 83 \\
\hline 2004 & South Sudan & SUDV & 17 & 7 & 41 \\
\hline 2005 & Republic of Congo & EBOV & 12 & 10 & 83 \\
\hline 2007 & Democratic Republic of Congo & EBOV & 264 & 187 & 71 \\
\hline 2007-2008 & Uganda & BDBV & 149 & 37 & 25 \\
\hline 2008-2009 & Democratic Republic of Congo & EBOV & 32 & 15 & 47 \\
\hline 2011 & Uganda & SUDV & 1 & 1 & 100 \\
\hline 2012 & Uganda & SUDV & 11 & 4 & 36 \\
\hline 2012 & Democratic Republic of Congo & Bundibugyo & 36 & 13 & 36 \\
\hline 2012 & Uganda & SUDV & 6 & 3 & 50 \\
\hline 2014 & Democratic Republic of Congo & EBOV & 69 & 49 & 71 \\
\hline 2014 & Guinea & EBOV & 3814 & 2544 & 67 \\
\hline 2014 & Liberia & EBOV & 10678 & 4810 & 45 \\
\hline 2014 & Sierra Leone & EBOV & 14124 & 3659 & 26 \\
\hline 2014 & Nigeria & EBOV & 20 & 8 & 40 \\
\hline 2014 & Mali & EBOV & 8 & 6 & 75 \\
\hline 2017 & Democratic Republic of Congo & EBOV & 8 & 4 & 50 \\
\hline 2018 & Democratic Republic of Congo & EBOV & 54 & 33 & 61 \\
\hline 2018-2019 & Democratic Republic of Congo & EBOV & 3220 & 2150 & 67 \\
\hline 2019 & Uganda & EBOV & 4 & 4 & 100 \\
\hline Total & & & 34356 & 14823 & \\
\hline
\end{tabular}

Source: WHO, Centers for Disease Control and Prevention (https://www.cdc.gov/vhf/ebola/history/chronology.html), MacNeil and Rollin, ${ }^{16}$ Baize et al, ${ }^{6}$ Nsio et al..$^{30}$

${ }^{*}$ On going outbreak

BDBV, Bundibugyo ebolavirus; CFR, case fatality rate; EBOV, Ebola virus ; EVD, Ebola virus disease; SUDV, Sudan Ebola virus; TAFV, Taï Forest ebolavirus .

surrounding this and other potential Ebola therapeutics is ensuring the availability and affordability of any drug that proves effective. ${ }^{22} 4344$

The EVD epidemic in the DRC has identified two new drugs that can dramatically cut mortality from the disease. The two drugs were immediately offered to all patients to control the country's worst-ever outbreak. A clinical trial comparing four potential drugs, namely ZMapp, remdesivir, mAb114 and REGN-EB3, showed that the latter met the criteria to stop the outbreak. Among all patients who took the drugs, those treated with REGN-EB3 had a mortality rate of $29 \%$, which was lower compared with patients treated with mAb114 and ZMapp. More than $75 \%$ of those who received no treatment died during the 


\begin{tabular}{|c|c|c|c|c|}
\hline Characteristics & Category & Case & Death & CFR (\%) \\
\hline \multirow[t]{2}{*}{ Gender } & Male & 15803 & 6373 & 46 \\
\hline & Female & 18553 & 8449 & 54 \\
\hline \multirow[t]{3}{*}{ Age group (years) } & $0-15$ & 7215 & & \\
\hline & $15-60$ & 24049 & & \\
\hline & $60+$ & 2192 & & \\
\hline \multirow{2}{*}{$\begin{array}{l}\text { Type of contact/ } \\
\text { source of infection }\end{array}$} & Health facility & 13742 & & \\
\hline & Household & 20614 & & \\
\hline Occupation & $\begin{array}{l}\text { Healthcare } \\
\text { worker }\end{array}$ & & & \\
\hline
\end{tabular}

CFR, case fatality rate; EVD, Ebola virus disease.

epidemic. ${ }^{67}$ Early discontinuation may overestimate the treatment effect at an earlier time point and decrease the ability to detect long-term advantages and disadvantages of the intervention, particularly if the intervention is intended to be a lifelong therapy. Additionally, early discontinuation of a trial may decrease the precision of results with fewer data points.

A highly efficacious vaccine has been used to immunise more than 111000 people in the DRC since the outbreak was declared in August 2018. However, the mortality rate in this outbreak is around $67 \%$, which is comparable with the mortality rate during the West African 2014-2016 epidemic. Vaccination strategy is currently limited to a ring approach, ${ }^{10} 4546$ in which only direct and indirect contacts of probable and confirmed Ebola cases, or frontline health workers and humanitarian staff, are targeted. Some challenges have been identified in the provision of vaccination in the DRC, where more than a year only a quarter of known and probable Ebola contacts were traced by national surveillance teams. The current vaccination strategy works in preallocated vaccination sites and has a fixed number of daily doses. Persisting fears and misconceptions around the vaccine among local communities are probable factors that pose additional challenges for vaccination uptake. ${ }^{10}$

\section{Health system vulnerability}

Long before the Ebola crisis, access to healthcare services and safe drinking water and sanitation in Sub-Saharan Africa were inadequate. To date, there are marked inequalities between regions, socioeconomic groups and genders. ${ }^{47}$ The cost to individuals in getting healthcare services is high, with a greater level of inequality. In most of the EVD outbreaks, most healthcare facilities were unable to safely provide the services needed, as they lacked staff, medicine and health information. ${ }^{48}$ During the EVD outbreak in West Africa, the health system was unable to handle an emergency, let alone continue to run existing services. ${ }^{47}$ Affected countries were unable to contain EVD within their borders. Limited access to screening and diagnosis, poor pre-existing surveillance mechanisms, overstretched isolation facilities, and lack of treatment to reduce morbidity have been described to largely contribute to the uncontrolled transmission of EVD in West Africa and DRC. ${ }^{29}$ Gap in healthcare still exists in EVD outbreak areas whereas even after several years, difficulties in identifying and following up cases and contacts of Ebola are the main challenges. In the recent outbreak in DRC, the first case was confirmed in Goma, the capital of North Kivu, and a city of one million people. The patient had to travel from Butembo to Goma to seek healthcare service. Over 3 months, only a third of new Ebola cases were identified and monitored as contacts of previously confirmed cases, while two-thirds of contacts were never followed up by the surveillance teams. People continued to die in their communities, undiagnosed and untreated. In both the West Africa and DRC outbreaks, the countries faced a significant reduction in the utilisation of health facilities, including paediatric all-cause and malaria admissions, maternity admissions, and attendance in the community. ${ }^{3}$ New patients with Ebola are confirmed and isolated with an average delay of 5 days after showing symptoms, during which time they are both infectious and are being denied early treatments, decreasing their chances of survival.

\section{Sociocultural and economic factors}

A complex suite of sociocultural and economic factors influence human movement across the landscape and can have critical impacts on outbreak dynamics and the spatial spread of the infectious disease. ${ }^{27} 28$ Because of the nature of its transmission, EVD is particularly influenced by sociocultural and behavioural events related to caring for the sick, deaths, burial, funerals and mourning practices. ${ }^{49}$ Adherence to ancestral funeral and burial rites has been singled out as fuelling large explosions of new cases in EVD high-risk areas. ${ }^{49}$ Moreover, community

Table 3 OR for case fatality rate of Ebola virus disease according to period

\begin{tabular}{|c|c|c|c|c|}
\hline & \multicolumn{4}{|l|}{ Year of outbreak } \\
\hline & 1976-1986 & $1987-1997$ & 1998-2008 & 2009-2019 \\
\hline Death (n) & 454 & 348 & 733 & 13288 \\
\hline OR $(95 \% \mathrm{Cl})$ & $1.6(1.4$ to 1.8$)$ & $1.7(1.5$ to 1.9$)$ & $1.4(1.3$ to 1.6$)$ & 1.6 (1.5 to 1.6$)$ \\
\hline$P$ value & $<0.001$ & $<0.001$ & $<0.001$ & $<0.001$ \\
\hline
\end{tabular}




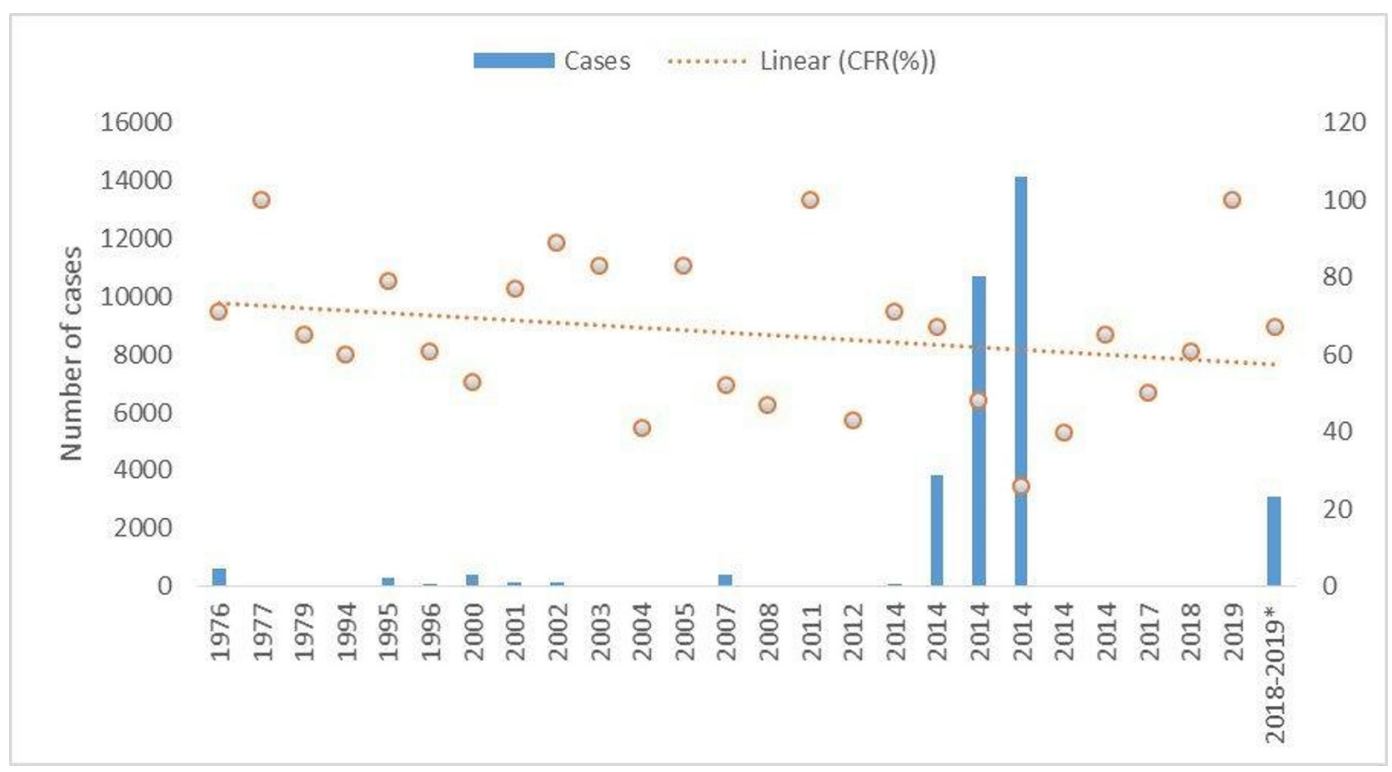

Figure 3 Number of Ebola cases and case fatality rate (CFR) in Sub-Saharan Africa, 1976-2019.

or social resistance has been reported as a challenge in many instances of EVD outbreaks. To some extent, resistance was due to the limited involvement of members of the community in epidemic responses. ${ }^{3135}$ Usually, highly infectious disease outbreaks are associated with fear, avoidance, misunderstanding and stigmatisation. These factors have been shown to contribute to community mistrust of healthcare systems, and hence poor healthseeking behaviour. ${ }^{50}$

\section{Opportunities for future prevention and control}

Integrating community-based, one-health approach

Challenges in EVD control highlight the necessity of broad-based (one-health) infectious disease surveillance and emergency response practices. Integrating community-based, one-health surveillance in already established initiatives is likely to address EVD outbreak control. One-health approach is likely to provide a good understanding of the drivers of spillover events from forest-dwelling fauna to forest interfacing humans, which will enable Ebola prevention and control at source. To reduce the risk of wildlife-to-human and human-tohuman transmission, public health officials need to

\begin{tabular}{|c|c|c|c|}
\hline Factor & Challenge & Opportunity & Action \\
\hline $\begin{array}{l}\text { Epidemiological } \\
\text { and ecological } \\
\text { factors }\end{array}$ & $\begin{array}{l}\text { Ebola viruses are } \\
\text { endemic in central } \\
\text { and western African } \\
\text { rainforests. }\end{array}$ & $\begin{array}{l}\text { Known EVD endemic } \\
\text { country. } \\
\text { Establishing the magnitude } \\
\text { of EVD in endemic countries. }\end{array}$ & $\begin{array}{l}\text { Consolidate knowledge on the magnitude } \\
\text { and health determinants of infectious } \\
\text { disease epidemics in all endemic and } \\
\text { countries at high risk. }\end{array}$ \\
\hline $\begin{array}{l}\text { Health system } \\
\text { factors }\end{array}$ & $\begin{array}{l}\text { Limited laboratory } \\
\text { capacities. } \\
\text { Weak surveillance } \\
\text { systems. } \\
\text { Lack of effective } \\
\text { therapeutics and } \\
\text { vaccines. } \\
\text { Inadequate budget for } \\
\text { the healthcare system. }\end{array}$ & $\begin{array}{l}\text { Availability of molecular } \\
\text { and serological laboratory } \\
\text { techniques. } \\
\text { Adoption of one-health } \\
\text { surveillance. } \\
\text { Improving self-regulation. } \\
\text { Country's political will and } \\
\text { involvement of partners. }\end{array}$ & $\begin{array}{l}\text { Strengthen capacity for detection, } \\
\text { identification and response, including } \\
\text { laboratory infrastructure and human } \\
\text { capacity; implement one-health } \\
\text { surveillance; development of early } \\
\text { warning systems.Conduct of clinical trial } \\
\text { on available and new therapeutic and } \\
\text { vaccine candidates. } \\
\text { Resource mobilisation. }\end{array}$ \\
\hline $\begin{array}{l}\text { Sociocultural } \\
\text { factors }\end{array}$ & $\begin{array}{l}\text { High-risk behaviours. } \\
\text { Limited community } \\
\text { involvement. }\end{array}$ & $\begin{array}{l}\text { Adoption of one-health } \\
\text { approach in engaging } \\
\text { communities in most } \\
\text { countries. } \\
\text { Availability of information and } \\
\text { communication technologies. }\end{array}$ & $\begin{array}{l}\text { Strengthen public health education } \\
\text { and promotion using various channels, } \\
\text { including social media. } \\
\text { Empowering individuals and } \\
\text { communities. }\end{array}$ \\
\hline
\end{tabular}

EVD, Ebola virus disease. 
emphasise that EVD results from direct contact with blood, secretion and excretion of infected humans or animals, or indirectly through contact with contaminated fomites, environment or objects. A better understanding of the ecology of wild animals concerning pathogen transmission is critical to the overall control of EVD in Africa.

The one-health paradigm provides opportunities for public education and control because EVD is an animal virus that is transmitted to humans. ${ }^{51-53}$ Getting to the root of EVD control, therefore, requires continuous collective partnership and engagement of human and animal health sectors. This entails a comprehensive collation/analysis of data from both sectors which should be used to plan effective interventions in the forest environment, wildlife, and animal and human health interface.

\section{Research and development for novel diagnostic tool, drugs and safe vaccines}

Building early warning indicators and rapid response to adequately prevent or respond to the EVD outbreak is needed. Scaling up access to medical supplies and vaccine stockpiles is equally important. Available drugs and vaccines should be added to supplies of personal protective effects and biosafety measures and medicine for supportive care that are given to areas at risk of EVD. ${ }^{44}{ }^{54}$ Undersupply or oversupply can be a challenge due to the quantities needed since an epidemic cannot be predicted. It is, therefore, important to ensure that tests and laboratory analysis to confirm suspected cases as soon as possible are readily accessible. Although knowledge on EVD may be higher among medical practitioners ${ }^{55}$ low access to an affordable simple test for timely diagnosis and confirmation can result in a widespread outbreak in affected areas. As the race towards the availability of therapeutic and vaccine development continues, accelerating research and development for novel diagnostic tools, drugs and safe vaccines is important. The decision to stop a clinical trial early must ensure a careful balance between the integrity of the trial and accuracy of the study results versus preventing harm in patients randomised to inferior treatment and the rapid dissemination to broader medical community. The vaccination that protects both human communities and the fauna they interact with (shared immunity) can be one of the novel intervention approaches.

Sub-Saharan countries need to improve their disease surveillance systems and scale up access to routine immunisation programmes. Investing in the development and implementation of local and regional therapeutic and immunisation programmes and virus transmission dynamic interaction requires a multipronged approach with the support of effective cold chain, follow-up tracking system, and contextual communication to establish trust and confidence with vulnerable communities.

\section{Health system resilience}

The health system includes health facilities, medical personnel and numerous stakeholders (people, organisations and activities) working in a concerted effort with the paramount intention of maintaining, restoring and improving health across both individuals and groups. The control of EVD is a desire of any region in order to plan and build a resilient health system. Such a system should have a service delivery, health workforce, information, medical products, vaccine and technologies, financing, and good governance to deliver high-quality and efficient health services. ${ }^{36}$ Africa needs integrated approaches to care for diverse needs-working with non-state actors to mobilise and expand its primary care capacity in the public and private sectors. Currently, outbreak relief focuses on short-term assistance delivered by multiple organisations. The long-term solutions would be to make primary healthcare the centre platform of response. Scaling up contextually diagnostic and care access at the point of need is essential to improving the quality of life and productivity of vulnerable populations. Important components such as governance, leadership and funding are needed to improve medicine access and logistics, human resource capacity for healthcare services delivery, and information technology uptake in health system strengthening.

\section{Community involvement and empowerment}

Social science approaches such as anthropology, working closely with other disciplines, are becoming increasingly important in addressing EVD and other disease outbreaks through surveillance, response, community preparedness and health system strengthening. Local practices in caring for the sick at home and in health facilities and the perceptions thereof, the handling of the dead and funeral arrangements, the role of complementary medicine and local traditional healers in healthcare, as well as documentation of actual healthcare options used by members of the community need to be addressed before and after epidemics. Equally important is knowledge of local interactions with modern technologies, establishing and re-establishing healthcare relationships, local social structure, community engagement and communication during outbreaks. ${ }^{50}$

Community engagement and participation are an important factor in the appropriate containment of an outbreak and in preventing its further transmission..$^{56-58}$ Ensuring community participation is not only a key strategy to control the disease in affected areas but also a crucial link in those areas where no case of EVD has been detected. ${ }^{405960}$ Sustained engagement and communication with community groups help to build trust and confidence in response efforts and enable community participation and actions. ${ }^{61-64}$ Thus, a strong emphasis on educating and empowering individuals and communities should be the first step to consider in the fight against EVD and other infectious disease epidemics. Application of appropriate and effective risk communication strategies 
in improving dissemination and uptake of public health messages is also critical to the achievement of this goal. Contemporary increase in consumer/provider-generated information and communication technology and application, social media penetration and acceptance, online disease data and information literacy, and communication in emergency response should be exploited to optimise health benefit.

\section{CONCLUSIONS}

The findings of this review advocate the need to develop a strategy to reduce transmission between human beings and wildlife through a shared commitment, as part of the solution to the future control of EVD outbreaks. Current EVD control measures such as case management, vaccination, active surveillance, case identification and isolation, and strategic community engagement have helped to contain outbreaks, but many people still die and more epidemics are likely to occur in the previously affected and new geographical areas. To improve the situation, research on the role of wildlife in the transmission of EVD should be undertaken. There is also a need to accelerate research and development for novel diagnostic tools, drugs, and safe and efficacious vaccines. Wildlife surveillance data on the biodiversity of bats and primates that are found in the region and on the Ebola virus activity in animals and humans should also be included in strategic interventions. Overall, the success of EVD control requires a balance between bioscience, including the role of epidemiology, health systems, socioanthropology and political science, all brought together to facilitate early detection and response to unusual disease events. Moreover, documenting how diseases are conceptualised is the first step towards understanding local healthcare pathways and unpacking the different meanings attached to infectious diseases in a diversity of communities. This should include the sources of such knowledge, and the past and current influences on the knowledge of these infectious diseases. A multipronged approach with the support of effective cold chain, follow-up tracking system, and contextual communication to establish trust and confidence with vulnerable communities is an equally important component in attaining national and global health security.

\section{Author affiliations \\ ${ }^{1}$ SACIDS Foundation for One Health - Africa Centre of Excellence for Infectious Diseases of Human and Animals, Sokoine University of Agriculture, Chuo Kikuu, Tanzania \\ ${ }^{2}$ Department of Microbiology and Immunology, Muhimbili University of Health and Allied Sciences, Dar es Salaam, Tanzania \\ ${ }^{3}$ Department of Health Science and Technology, Mbeya University of Science and Technology, Mbeya, Tanzania \\ ${ }^{4}$ Department of Arbovirology, Emerging and Re-emerging Infectious Diseases, Uganda Virus research Institute, Entebbe, Uganda \\ ${ }^{5}$ National Institute of Communicable Diseases, National Laboratory Services, Johannesburg, South Africa}

Contributors All authors have equally contributed to this work.
Funding The authors have not declared a specific grant for this research from any funding agency in the public, commercial or not-for-profit sectors.

Map disclaimer The depiction of boundaries on the map(s) in this article do not imply the expression of any opinion whatsoever on the part of BMJ (or any member of its group) concerning the legal status of any country, territory, jurisdiction or area or of its authorities. The map(s) are provided without any warranty of any kind, either express or implied.

Competing interests None declared.

Patient consent for publication Not required.

Provenance and peer review Not commissioned; externally peer reviewed.

Data availability statement Data are available upon request.

Open access This is an open access article distributed in accordance with the Creative Commons Attribution Non Commercial (CC BY-NC 4.0) license, which permits others to distribute, remix, adapt, build upon this work non-commercially, and license their derivative works on different terms, provided the original work is properly cited, appropriate credit is given, any changes made indicated, and the use is non-commercial. See: http://creativecommons.org/licenses/by-nc/4.0/.

\section{REFERENCES}

1 Rewar S, Mirdha D. Transmission of ebola virus disease: an overview. Ann Glob Health 2014;80:444-51.

2 WHO. World Health Organization. Ebola hemorrhagic fever in Zaire, 1976. Bull World Health Organ 1978;56:271-93.

3 World Health Organisation. Ebola virus disease: the Democratic Republic of the Congo. External situation report 2019;b:52.

4 Okware SI, Omaswa FG, Zaramba S, et al. An outbreak of Ebola in Uganda. Trop Med Int Health 2002;7:1068-75.

5 Towner JS, Sealy TK, Khristova ML, et al. Newly discovered Ebola virus associated with hemorrhagic fever outbreak in Uganda. PLoS Pathog 2008;4:e1000212.

6 Baize S, Pannetier D, Oestereich L, et al. Emergence of Zaire Ebola virus disease in guinea. N Engl J Med 2014;371:1418-25.

7 Maganga GD, Kapetshi J, Berthet N, et al. Ebola virus disease in the Democratic Republic of Congo. N Engl J Med 2014;371:2083-91.

8 Aurelie KK, Guy MM, Bona NF, et al. A historical review of Ebola outbreaks. Advances in Ebola control. InTech Open 2017;2:1-27.

9 Muyembe-Tamfum JJ, Mulangu S, Masumu J, et al. Ebola virus outbreaks in Africa: past and present. Onderstepoort $J$ Vet Res 2012;79:8.

10 Coltart CEM, Lindsey B, Ghinai I, et al. The Ebola outbreak, 20132016: old lessons for new epidemics. Philos Trans R Soc Lond B Biol Sci 2017;372:20160297.

11 Munster VJ, Bausch DG, de Wit E, et al. Outbreaks in a rapidly changing central Africa - lessons from Ebola. N Engl J Med 2018;379:1198-201.

12 Majid MU, Tahir MS, Ali Q, et al. Nature and history of Ebola virus: an overview. Arch Neurosci 2016;3:e35027.

13 Sheskin DJ. Handbook of parametric and nonparametric statistical procedures. 3rd edn. Boca, 2004.

14 Alexander KA, Sanderson CE, Marathe M, et al. What factors might have led to the emergence of Ebola in West Africa? PLoS Negl Trop Dis 2015;9:e0003652.

15 Groseth A, Feldmann H, Strong JE. The ecology of Ebola virus. Trends Microbiol 2007;15:408-16.

16 MacNeil A, Rollin PE. Ebola and Marburg hemorrhagic fevers: neglected tropical diseases? PLoS Negl Trop Dis 2012;6:e1546.

17 Sanchez A, Geisbert TW, Feldmann H. Filoviridae: Marburg and Ebola Viruses. In: Knipe DM, Howley PM, eds. Fields virology. Philadelphia: Lippincott Williams and Williams, 2007: 1409-48.

18 Zheng H, Yin C, Hoang T, et al. Ebolavirus classification based on natural vectors. DNA Cell Biol 2015;34:418-28.

19 Tong Y-G, Shi W-F, Liu D, et al. Genetic diversity and evolutionary dynamics of Ebola virus in Sierra Leone. Nature 2015;524:93-6.

20 Carroll SA, Towner JS, Sealy TK, et al. Molecular evolution of viruses of the family Filoviridae based on 97 whole-genome sequences. $J$ Virol 2013;87:2608-16.

21 Check Hayden E, Hayden E. The Ebola questions. Nature 2014;514:554-7.

22 Oleribe OO, Salako BL, Ka MM, et al. Ebola virus disease epidemic in West Africa: lessons learned and issues arising from West African countries. Clin Med 2015;15:54-7.

23 Centers for Disease Control and Prevention, 2014-2016 Ebola Outbreak in West Africa | History | Ebola (Ebola Virus Disease) | CDC 
[Internet]. Cdc.gov, 2019. Available: https://www.cdc.gov/vhf/ebola/ history/2014-2016-outbreak/index.html [Accessed 1 Nov 2019].

24 Formenty $\mathrm{P}$, Boesch $\mathrm{C}$, Wyers $\mathrm{M}$, et al. Ebola virus outbreak among wild chimpanzees living in a rain forest of Côte d'Ivoire. $J$ Infect Dis 1999;179:S120-6.

25 Omoleke SA, Mohammed I, Saidu Y. Ebola viral disease in West Africa: a threat to global health, economy and political stability. $J$ Public Health Africa 2016;7:534.

26 Selvaraj SA, Lee KE, Harrell M, et al. Infection rates and risk factors for infection among health workers during Ebola and Marburg virus outbreaks: a systematic review. J Infect Dis 2018;218:S679-89.

27 Dyer O. Two Ebola treatments halve deaths in trial in DRC outbreak. BMJ 2019;366:I5140.

28 Nkangu MN, Olatunde OA, Yaya S. The perspective of gender on the Ebola virus using a risk management and population health framework: a scoping review. Infect Dis Poverty 2017;6.

29 Wonderly B, Jones S, Gatton ML, et al. Comparative performance of four rapid Ebola antigen-detection lateral flow immunoassays during the 2014-2016 Ebola epidemic in West Africa. PLoS One 2019;14:e0212113.

30 Nsio J, Kapetshi J, Makiala S, et al. 2017 outbreak of Ebola virus disease in northern Democratic Republic of Congo. $J$ Infect Dis 2019:jiz107.

31 Liu W, Li Z, Du Y, et al. Ebola virus disease: from epidemiology to prophylaxis. Military Med Res 2015;2:7.

32 Meseko CA, Egbetade AO, Fagbo S. Ebola virus disease control (in West Africa): an ecological, one health approach. Pan Afr Med J 2015;21:6.

33 Kieny MP, Dovlo D. Beyond Ebola: a new agenda for resilient health systems. Lancet 2015;385:91-2.

34 Olivero J, Fa JE, Real R, et al. Recent loss of closed forests is associated with Ebola virus disease outbreaks. Sci Rep 2017;7:14291.

35 Capps B, Lederman Z. One health, vaccines and Ebola: the opportunities for shared benefits. J Agric Environ Ethics 2015:28:1011-32.

36 Chippaux J-P. Outbreaks of Ebola virus disease in Africa: the beginnings of a tragic SAGA. J Venom Anim Toxins Incl Trop Dis 2014;20:442014:44.

37 Neiderud C-J. How urbanization affects the epidemiology of emerging infectious diseases. Infect Ecol Epidemiol 2015;5:27060.

38 The GD. Ebola virus disease outbreak in West Africa. $J$ Gen Virol 2014;2014:1619-24.

39 Olival K, Hayman D. Filoviruses in bats: current knowledge and future directions. Viruses 2014:6:1759-88.

40 Caron A, Bourgarel M, Cappelle J, et al. Ebola virus maintenance: if not (only) bats, what else? Viruses 2018;10:5492018.

41 Roddy P, Colebunders R, Jeffs B, et al. Filovirus hemorrhagic fever outbreak case management: a review of current and future treatment options. J Infect Dis 2011;204:S791-5.

42 Mire CE, Geisbert JB, Marzi A, et al. Vesicular stomatitis virusbased vaccines protect nonhuman primates against Bundibugyo ebolavirus. PLoS Negl Trop Dis 2013;7:e2600.

43 Houlihan CF, Youkee D, Brown CS. Novel surveillance methods for the control of Ebola virus disease. Int Health 2017;9:139-41.

44 Jones KE, Patel NG, Levy MA, et al. Global trends in emerging infectious diseases. Nature 2008;451:990-3.
45 Marzi A, Feldmann $\mathrm{H}$. Ebola virus vaccines: an overview of current approaches. Expert Rev Vaccines 2014:13:521-31.

46 Elston JW, Moosa AJ M, et al. Impact of the Ebola outbreak on health systems and population health in Sierra Leone. J Publ Health 2016;38:673-8.

47 Pinzon JE, Wilson JM, Tucker CJ, et al. Trigger events: enviroclimatic coupling of Ebola hemorrhagic fever outbreaks. Am J Trop Med Hyg 2004;71:664-74.

48 Madelain V, Nguyen THT, Olivo A, et al. Ebola virus infection: review of the pharmacokinetic and pharmacodynamic properties of drugs considered for testing in human efficacy trials. Clin Pharmacokinet 2016;55:907-23.

49 Thiam S, Delamou A, Camara S, et al. Challenges in controlling the Ebola outbreak in two prefectures in guinea: why did communities continue to resist? Pan Afr Med J 2015;22:22.

50 Johnson O, Youkee D, Brown CS, et al. Ebola holding units at government hospitals in Sierra Leone: evidence for a flexible and effective model for safe isolation, early treatment initiation, Hospital safety and health system functioning. BMJ Global Health 2016;1:e000030

51 Manguvo A, Mafuvadze B. The impact of traditional and religious practices on the spread of Ebola in West Africa: time for a strategic shift. Pan Afr Med J 2015;22:9.

52 Moran B. Fighting Ebola in conflict in the Dr Congo. Lancet 2018;392:1295-6.

53 Marí Saéz A, Weiss S, Nowak K, et al. Investigating the zoonotic origin of the West African Ebola epidemic. EMBO Mol Med 2015;7:17-23.

54 Swanepoel R, Leman PA, Burt FJ. Experimental inoculation of plants and animals with Ebola virus. Emerg Infect Dis 1996;2:321-5.

55 Pathmanathan I, O'Connor KA, Adams ML, et al. Rapid assessment of Ebola infection prevention and control needs-six districts, Sierra Leone. MMWR Morb Mortal Wkly Rep 2014;63:1172-4.

56 World Health Organization. Infection prevention and control (IPC) guidance summary: Ebola guidance package. Geneva, Switzerland: World Health Organization, 2014. Available: http://www.who.int/csr/ resources/publications/ebola/evd-guidance-summary/en

57 Hamid KM, Yusuf I, Onoja BA, et al. Knowledge, attitude and practice of medical laboratory practitioners in the fight against Ebola virus disease. J Virus Erad 2018;4:1-5.

58 Chan M. Ebola virus disease in West Africa - no early end to the outbreak. N Engl J Med 2014;371:1183-5.

59 Frieden TR, Damon I, Bell BP, et al. Ebola 2014 - new challenges, new global response and responsibility. N Engl J Med 2014;371:1177-80.

60 Wilkinson A, Fairhead J. Comparison of social resistance to Ebola response in Sierra Leone and guinea suggests explanations lie in political configurations not culture. Crit Public Health 2017;27:14-27.

61 Dhillon RS, Kelly JD. Community trust and the Ebola endgame. N Engl J Med 2015;373:787-9.

62 Petherick A. Ebola in West Africa: learning the lessons. Lancet 2015;385:591-2

63 Kruk ME, Myers M, Varpilah ST, et al. What is a resilient health system? Lessons from Ebola. Lancet 2015;385:1910-2.

64 Oliver N, Matic A, Frias-Martinez E. Mobile network data for public health: opportunities and challenges. Front Public Health 2015;3:189 